\title{
Digital architectural reconstruction: new media technology and their use as educational tools in the Arabian Gulf
}

\author{
R. W. Hawker \\ Department of Art and Design, Zayed University, Dubai, UAE
}

\begin{abstract}
The Department of Art and Design at Zayed University has instigated a collaborative research project incorporating faculty and student work in cooperation with the archaeological staff at the National Museum of Ras alKhaimah focused on documenting the vernacular architecture of Ras alKhaimah. The project is important for a number of reasons, including the massive development now undertaken in the United Arab Emirates and the fact that all our students are female in a still male-dominated society.

Keywords: traditional architecture, reconstruction, Arab and Islamic world, United Arab Emirates.
\end{abstract}

\section{Introduction}

At the Department of Art and Design in Zayed University in Dubai, United Arab Emirates (UAE), students and faculty are working together in collaboration with staff from the National Museum of Ras al-Khaimah. We are using digital media to record and document historic material culture, especially traditional architecture, in the northern emirate of Ras al-Khaimah.

While the technical applications of these programs has led to fascinating results from the perspective of historians, the use of new media to record old ideas touches on a number of sociological issues specific to the cultural context in which we work. Our use of digital media to document, reconstruct and explore historic architecture is drawing us into a series of contradictions. In a society obsessed by modernity and sometimes bewildered by its spectacular jump from pre-industrial to post-modern, new media bridges the gap between 
generations and reinforces the importance of tradition in providing social stability.

In order to understand the social significance of this project and the issues it intersects is important to examine the history and environment of the UAE and thus to see the present generation within the context of the massive social change the country has undergone since the rise of oil. The use of digital media to explore architectural history is useful and instructive on its own, but the way in which students have responded to the content is profoundly significant for this otherwise young nation-state.

\section{The UAE}

The UAE is a peninsular country located on the southwestern side of the Arabian Gulf and on the northwestern banks of the Gulf of Oman. The UAE controls the third largest proven oil reserve in the world [1] and consists of seven emirates: Abu Dhabi, Dubai, Sharjah, Ajman, Umm al-Qawain, Ras al-Khaimah, and Fujairah. Ras al-Khaimah is located at the north of the peninsula as the environmental zones draw closer together and fade into the mountainous Omani province of Musandam.

Historic documentation and archaeological research reveal that Ras alKhaimah was able to support a larger population because of the closeness of its environmental zones. By the late Abbasid period, the coastal port of Julfar emerged as an important trans-shipment center for goods carried in from the Indian Ocean to the ports of the upper Gulf. The different economic activities were controlled by the patchwork of tribes occupying the area and managed through the tribal kinship system.

The path leading to the establishment of the UAE was begun in the last quarter of the eighteenth century. The British government branded the area the Piracy Coast and began the systematic pacification of Gulf tribes, resulting in the signing of a series of truces and agreements, beginning in 1820 at Al Falayya in Ras al-Khaimah. This established the area as a British protectorate and tied it to the development of British India trade, culminating in an era of prosperity based primarily on pearl fishing and trading in the first quarter of the twentieth century [2]. Oil surveying gained momentum in the 1950s and 1960s, and funds from the oil and gas industries fueled the rapid growth in the physical and social infrastructure of the country in the two decades following confederation [3]. Ras al-Khaimah found itself in the peculiar situation of pre-oil wealth and post-oil poverty. Urban development, although now accelerating, has not reached the alarming rate of its southern neighbors, Dubai, Abu Dhabi, and Sharjah and thus substantial stands of historic architecture still remain scattered throughout its landscape.

\subsection{The UAE Today: Zayed University and Dubai}

Dubai is both a city and an emirate that best exemplifies the new UAE. The rise in oil exports since 1971 have created structural changes in the UAE's economy, 
creating diversification by directing funds raised through oil exports to, first, industrialism [4], and, second, to service sectors of the economy. Dubai has thus reconfigured itself as a hub of all modern infrastructural activities in the Gulf, creating a series of city quarters dedicated to industrial and economic sectors. The best known of its current real estate development include the three Palm Islands that are now jutting out into the Gulf, and the Mall of the Emirates with its indoor ski hill. The dramatic reshaping of the traditional economic structure that these developments represent has torn the fine commercial and tribal net that connected the various villages and towns of the past. The settlement patterns changed with a dramatic shift towards increasing reliance on imported labor, now representing more than $90 \%$ of the labor market.

The federal government has increased its budget for education consistently over the last five years. Zayed University, for example, is a federal postsecondary institution for female citizens of the UAE with main campuses in Dubai and Abu Dhabi. The Department of Art and Design was established in 2001 and offers Bachelor of Arts' concentrations in a number of art and design disciplines, with the highest numbers of students enrolled in graphic design, interior design, and animation and motion graphics.

All the faculty are expatriate, often Anglophone North Americans, and most often trained in the United States. This complicates the issues of distance between students and faculty based on gender, ethnicity and often religion. For most faculties, their own experience of the Gulf and its culture is limited to Dubai, a city in which planners and developers have all but eliminated any vestiges of the past. There is no common memory of what life was like before oil among faculty as there is in the indigenous Emirati student body.

The students, however, retain a sense of connectedness to the past in their very names, which, according to local custom, include their given name, the names of four generations of male ancestors beginning with their fathers, and the family or tribal name (in Arabic: qabilah), which in turn often derives from a distant male ancestor. Also, following local Islamic custom, education is segregated by gender, and women are considered children until they are married and even then are under the supervision of their husbands. In order to embark on fieldtrips through the university the students must present a permission form signed by a male guardian. Women also follow Islamic strictures in their dress, typically keeping the hijab (covering their hair), and often wearing the naqab, a veil that covers their faces completely. It is not uncommon that a student's male faculty is the only male she has contact with outside of her immediate family.

\subsection{Documenting Ras al-Khaimah}

This cultural distance is at the heart of many systemic problems in education and design in the UAE. In a presentation exploring the obstacles to the conservation and regeneration of historic architecture in the UAE for the Sustainable City II conference organized by the Wessex Institute of Technology in Segovia, Spain in 2002, I argued that "[w]hile historic buildings are viewed with nostalgia, they are also not deemed suitable for contemporary life and have been isolated in the process of economic and social development. This situation was further 
exacerbated by unique demographic conditions in which few of either the builders or the educators actually come from the country itself. I further argued that " $[\mathrm{t}]$ he lack of curricula specific to the issues facing UAE society is common in most post-secondary institutions in the country. Its effects filter down to the lack of curricula and resources at the secondary and elementary levels of education as well. With few or no books on Emirati history, no specific courses, and a body of foreign faculty with limited knowledge of the country, it is difficult to instill an appreciation of past accomplishments among students, not only among those who will design the buildings but also among those who ultimately will pay for and use them" [5].

In response to the conditions I identified in 2002, I began to organize an integrative research program that involved both university faculty and students and cultural institutions in the community. I had been taking students on field trips for several years to Ras al-Khaimah, where Christian Velde, Ahmed Hilal, and Imke Moellering, the resident archaeologists at the National Museum of Ras al-Khaimah would introduce us to various archaeological and historic sites and ongoing museum-sponsored excavations and documentation projects. In 2003, we decided to intensify this relationship and involve the students directly in the museum's work through assigning in-field documentation exercises through related courses in Zayed University's Department of Art and Design. This immediately involved one of my colleagues, Omid Rouhani, an assistant professor in our interior design program, Chae Lee, a graphic designer, and Jason Demarte, a photographer with an interest in animation.

We scouted several sites across the different geographic zones of Ras alKhaimah, including Ras al-Khaimah town and mountain villages in Wadi Sham and at Halla, and identified two that were appropriate to our students: Jazirat alHamra, a coastal pearling port abandoned in the early 1970s but with substantial stands of older houses of coral and beach rock construction likely dating to the turn of the century, and two summer houses in the Shimal plains, an interior date cultivation area on the Hajar Mountains' alluvial fans. In addition, Demarte experimented with the software, Maya, as a rendering tool by reconstructing a typical mountain house from Wadi Sham.

Over the next three years, projects associated with Ras al-Khaimah were assigned in third and fourth year classes in interior and graphic design. Velde and the team at NMRAK helped supervise the field trips and provided additional support material, including historic photographs, satellite images, aerial photographs, and measured drawings. Annual field work with the university has now taken on an established pattern in which faculty meet with the archaeologists in October. We then visit new sites identified by the archaeologists, and map out a series of projects manageable within the constraints of the university curriculum that nonetheless support NMRAK's ongoing investigations.

Work has accelerated over the 2005-2006 academic year to include an ambitious project using the Global Positioning System (GPS), a satellite-based navigation system to plot the precise three-dimensional locations of houses and farming fields in a terraced mountain village using the GPS generated latitude, 
longitude and altitude readings. The information produced from the GPS readings was imported into an AutoCAD format, enabling Thomas Tucker, animation professor, and three of his animation classes to three-dimensionally reconstruct the building complexes, their surrounding environment, and the inhabitants. Tucker transferred the subsequent files into Maya, a rendering and animation software that has allowed him and his students to re-create the now abandoned buildings as a living village and provide a variety of virtual spatial experiences for the viewer. Students under graphic design professor Lee also completed a series of signage designs for six important heritage sites in Ras alKhaimah. Rouhani has expanded his students' documentation from an Iranianstyle badgir, or windtower, house in Jazirat al-Hamra to include the adjacent suq, or market, district.

\subsection{Jazirat al-Hamra}

Jazirat al-Hamra, sometimes referred to in historical documents as Jazira az$\mathrm{Za}$ 'ab, is a small island off the southern coast of Ras al-Khaimah in the United Arab Emirates and was occupied almost wholly by members of the Al Za'ab (singular Za'abi) tribe [6]. The majority of the Al Za'ab residents relocated from Jazirat al-Hamra to Abu Dhabi between 1969 and 1971, and left the old village as it stood. While the village was continuously inhabited throughout the $20^{\text {th }}$ century and houses were constantly upgraded, large clusters of coral and plaster houses dating to the turn of the century still stand. It is possible to reconstruct the early twentieth century settlement pattern and understand basic house styles and construction techniques.

Our students have been documenting individual houses and house clusters and speaking with elder members of the community about life in Jazirat alHamra prior to the village's abandonment. While this work is still ongoing, it is revealing important information on the location of various groups within the village and gives us insight into the possibility of variation of house style based on a combination of the residents' tribal affiliation and profession.

In this year's documentation, students prepared conventional documentation of the suq, or market district. Students used the measurements as well to render the buildings in Maya. Both conventional and digital elevations, plans, axonometric drawings and renderings were mounted on their presentation boards and exhibited at the Dubai campus along with the professional work of conservators with the Dubai Municipality in May 2006. Small files of these various projects have then been loaded up into a student intranet site created using Dreamweaver and made accessible to the university community as a whole.

\subsection{Shimal}

Although no work was done on the interior summer houses initially identified by NMRAK, one of our students, Mahra Al Mualla, identified a third, similar house in the Shimal district as belonging to her great grandfather, and over two semesters integrated family oral history into a reconstruction project in which 
she and a team of six other students first rendered and then created an animated fly-through of the house using Maya. The scale and detailing were initially based on the National Museum of Ras al-Khaimah's measured drawings. The students then deepened the reconstruction to include temporary additions, servants' quarters, and interior furnishings. The house is now located within a cemetery and therefore inaccessible to most visitors. The work of Al Mualla and her classmates provides audiences a virtual experience of the mass, space and furnishings of a historic building which most people will never have the chance to actually visit.

Al Mualla's interview with family members revealed that the house was used during the summer. Originally located within a large date garden, family members estimate the house to have been built between ninety and one hundred years ago. The earliest known owner of the house is Abdulla bin Rashid Al Mualla, the second husband of Mahra Mohammed Al Qassimi, and a member of the ruling lineage of the Al Ali tribe from Umm al-Qaiwain. The house was occupied in the months of July and August by the family. The trip from their residence in Sharjah to the house in Ras Al Khaimah took several days, depending on the tide. The house was occupied by Abdulla bin Rashid Al Mualla and his wife, as well as their six children. After Abdulla bin Rashid Al Mualla's passing, his widow married Khalid Al Qassimi, a former ruler of Sharjah and had her seventh child.

Al Mualla's research goes beyond simple documentation to illuminate the seasonal use of different sites and buildings and the ways in which status is articulated through the scale, materials and location of multiple buildings in relation to one another. Her reconstruction of the building with her classmates is based on oral history that reveals the acquisition and use of furnishings still owned by the family as well as the social use of the structure itself. These are significant contributions to how we understand traditional architecture and its relationship to social history.

\subsection{Barama}

In 2006, we obtained a small grant from the university to complete a GPS survey of a terraced, mountain farming village typical of the mountain-based Shihuh and related tribes of the northern UAE and Oman's Musandum peninsula. The subsequent data was transferred into AutoCAD format and used as the basis for a rendered reconstruction of the village. Students constructed three-dimensional simulations of some sixty houses and a number of terraces and farm fields, rendered the external facades and added details, such as water pots and weeds. Animated figures were then created to inhabit this virtual space. Costumes were based on historic photographs taken by Ronald Codrai in the late 1940s [7], Ramesh Shukla in the mid-1960s [8], and anthropologist Walter Dostal in the early 1970s [9] and facial features came from mapping the faces of male members of the students' families. The final result is brief animated fly-through video of the village and its inhabitants in an approximate reconstruction. This is a large and highly organized complex of farms and houses and represents a significant investment in time to build and maintain the walls and fields. Our 
ongoing research will follow the pattern of our work at Jazirat al-Hamra and integrate documentation, textual research and oral histories.

\section{Conclusion}

In a related but separate project for a fourth year art history class, two students, Wafa Al Shamsi and Asma Al Shamsi, researched dhow types, combining illustration work with ethnological interviews. The students have found they are treated with more respect than they are accustomed to due to the combination of their gender and age, mainly because they have expressed interest in a trade that their own brothers refuse to pick up and that is now dying out.

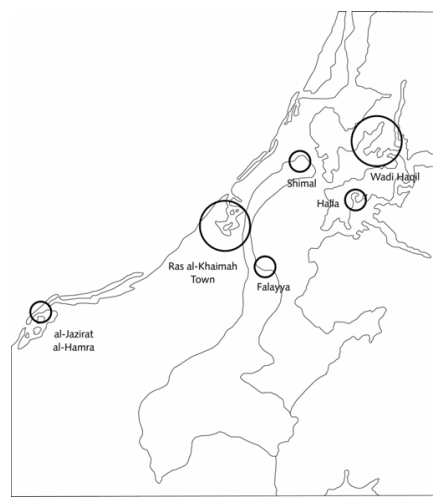

Figure 1: This map shows the locations of important sites investigated by Zayed University and the National Museum of Ras al-Khaimah in the emirate of Ras al-Khaimah in the UAE. (Illustration by Chae Lee.)

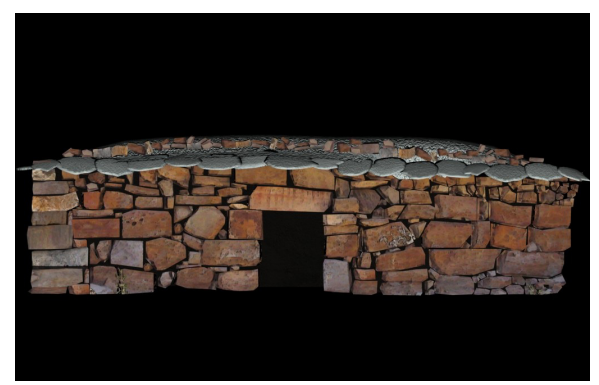

Figure 2: Virtual reconstruction of a Shihuh winter house by Zayed University design professor Jason Demartes. (Illustration by Jason Desmartes.)

This anecdote reveals some of the important intersections that the use of digital documentation plays in the contemporary UAE. First, it serves as a powerful tool in recording a series of traditions disrupted by the economic and 
social transformations of the oil era. Second, it brings disparate generations together through a shared interest in documenting the past and its practices. The students often demonstrate an aversion to traditional culture, and do not want to be contained within its limitations. Ironically, their embrace of new media and technology brings them back full-circle to their past and helps them reconnect to the stories and interests of the elder generations.

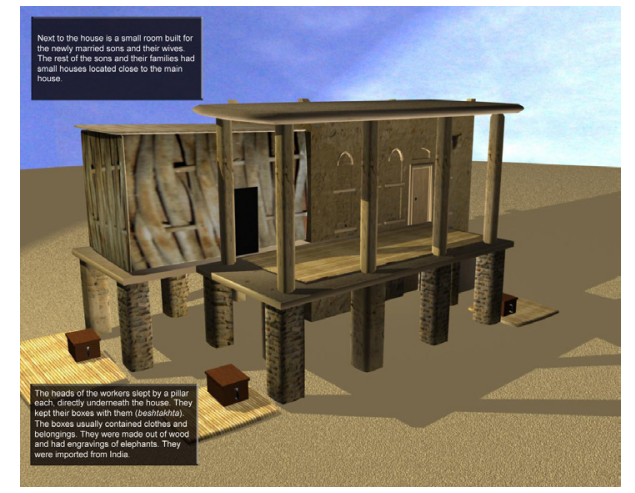

Figure 3: Digital reconstruction of the Abdulla bin Rashid Al Mualla house completed by a group of Zayed University students and led by Abdulla bin Rashid's great granddaughter Mahra Al Mualla. (Illustration courtesy of Mahra Al Mualla.)

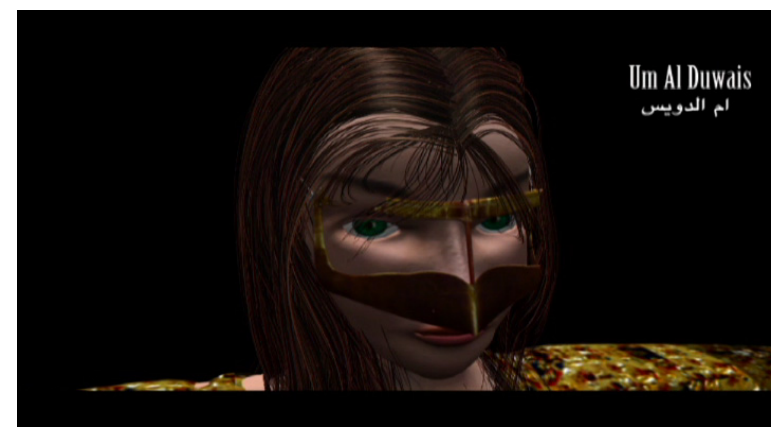

Figure 4: Zayed University student animated character for the animated flythrough of Barama. (Illustration courtesy of Thomas Tucker.)

\section{References}

[1] Al Abed, Ibrahim, Vine, Peter J. , \& Vine, Paula, editors, The United Arab Emirates 1996, Trident Press: London, p.99, 1996.

[2] See Al Qasimi, Sultan Bin Muhammad, Power Struggles and Trade in the Gulf, 1620-1820, University of Exeter Press and Forest Row: Exeter,1999. 
[3] Zahlan, Rosemaire Said, The Making of the Modern Gulf States, Ithaca Press: London, 1998.

[4] Shihab, Mohamed, Economic Development in the UAE, Abed and Hellyer, United Arab Emirates, pp.252-253

[5] Hawker, Ronald. "Where's the Air Conditioning Switch? Identifying problems in sustaining local architectural traditions in the contemporary United Arab Emirates," in C. A. Brebbia, J. F. Martin-Duque, and L. C. Wadhwa, editors, The Sustainable City II, Wessex: Wessex Institute of Technology Press Advances in Architecture Series Volume 14, 2002.

[6] Lorimer, J.G. The Gazetteer of the Persian Gulf, Oman and Central Arabia. London: Archive Editions, 1994.

[7] Codrai, Ronald. 1993. The North-East Shaikhdoms: An Arabian Album. Dubai: Motivate.

[8] Shukla, Ramesh, and Asha Bhatia. 1995. The UAE Formative Years 1965-1975: A Collection of Historical Photographs by Ramesh Shukla. Dubai: Motivate.

[9] Although we accessed these images in the archival collection at the National Museum of Ras al-Khaimah, some have been published in Walter Dostal, Dostal, Walter. The Traditional Architecture of Ras alKhaimah (North). Weisbaden: L. Reichert Verlag. 1983. 